\title{
Improvements in Operation Units of Car Welding Workshop
}

\author{
Qiqi He \\ ${ }^{1}$ School of North China Electric Power University, Baoding 071003, China \\ 289198812@qq.com
}

\begin{abstract}
In order to resolve the imbalance between station and process in the car welding workshop, we use the industrial engineering methods to improve operation units of welding workshop in the $\mathrm{X}$ car factory. Firstly, we collect the data by observing the employee's job and shooting video and recording the state before improvement. Secondly, we adopt program analysis and use the symbolic form records, determination of time and action analysis method of system to identify the improvement. Thirdly, we recognize the gap between cycle time and beat, and observe the effects after eliminate waste. Then, we balance the tasks with the principle of 80/20 to operation saturation. Finally, we evaluate the effect of improvement. The results show that the workers' operation time is shortened obviously and problems are resolved.
\end{abstract}

Keywords: Production efficiency, program analysis, 80/20, operation saturation.

\section{Background Introduction}

Welding workshop, as a hybrid line production system, pays attention to the establishment of the workshop and the implementation of reasonable and effective production operation schedule. We investigated the $\mathrm{X}$ car factory in Hebei, Baoding, China, with four major processes: stamping, welding, painting and assembly. We found the welding workshop in this factory initially stabled the division of each work station and eliminated the gap between various stations and processes to some extent. But there is still much room for improvement in unevenly producing. The specific problems are as follows: the waste during the production process, Imbalance between process assignments, much non-increment work and low production efficiency, etc.

\section{Program Analysis}

After initially stabling the division of each work station, carry out in-depth work to improve operation units and achieve the following:

(1) On-site path is optimal, the layout is reasonable.

(2) Processing and assembly process and operation steps down to a minimum.

(3) Process assignments are balanced. And operation saturation conform to the $80 / 20$ principle[1] that $80 \%$ of workers operation saturation is close to the beat whereas $20 \%$ is close to nearly $80 \%$ of the beat.

According to the operation video, we decompose the operation by taking action elements as the smallest unit. Then measure time, recognize improvement, operate classification and judge increment on one action element. Part of the results are shown in Table 1: 
Table 1 Program analysis table of part of the operation

\begin{tabular}{|c|c|c|c|c|c|c|c|}
\hline \multirow[b]{2}{*}{$\begin{array}{l}\text { Rout- } \\
\text { ine }\end{array}$} & \multirow{2}{*}{$\begin{array}{l}\text { Back } \\
\text { panel skin } \\
\text { weld }\end{array}$} & \multirow[b]{2}{*}{ IE } & \multirow{3}{*}{$\begin{array}{l}\text { symbol } \\
\text { Explainat- } \\
\text { ion }\end{array}$} & \multicolumn{4}{|l|}{$\begin{array}{l}\text { operation: } \\
\text { inspection: }\end{array}$} \\
\hline & & & & \multicolumn{4}{|c|}{$\begin{array}{l}\text { increment: VA } \\
\text { necessary non-increment: NVA } \\
\text { waste: W }\end{array}$} \\
\hline Name & $\begin{array}{l}\text { Worker } \\
\text { Mr.A1 }\end{array}$ & Engineer Mr.X & & \multicolumn{4}{|c|}{ cycle: R non-cycle operation: UR } \\
\hline $\begin{array}{l}\text { Time } \\
\text { line }\end{array}$ & $\begin{array}{l}\text { Operation } \\
\text { order }\end{array}$ & Operation details & $\begin{array}{l}\text { Operation } \\
\text { time }\end{array}$ & $\begin{array}{l}\text { Operation } \\
\text { classification }\end{array}$ & $\begin{array}{l}\text { Increment } \\
\text { judgment }\end{array}$ & Cycle & $\begin{array}{l}\text { Auxiliar } \\
\text { y list }\end{array}$ \\
\hline 5 & E1 & Wear gloves & 5 & 0 & NVA & $\mathrm{R}$ & 5 \\
\hline 33 & E2 & $\begin{array}{l}\text { Move the bench, } \\
\text { weld machine }\end{array}$ & 28 & $\rightarrow$ & W & UR & 28 \\
\hline 40 & E3 & $\begin{array}{l}\text { Wear a hat and face } \\
\text { mask }\end{array}$ & 7 & 0 & NVA & $\mathrm{R}$ & 7 \\
\hline 43 & E4 & On the bench & 3 & $\rightarrow$ & $\mathrm{W}$ & $\mathrm{R}$ & 3 \\
\hline 55 & E5 & $\begin{array}{l}\text { Trim the back-end } \\
\text { along the large } \\
\text { corrugated iron roof }\end{array}$ & 12 & ○ & W & $\mathrm{R}$ & 12 \\
\hline 72 & E6 & $\begin{array}{l}\text { Knock the back-end } \\
\text { along the large } \\
\text { corrugated iron roof } \\
\text { with hammers }\end{array}$ & 17 & $\square$ & W & $\mathrm{R}$ & 17 \\
\hline
\end{tabular}

Improving the identification of a point refers to the following dimensions:

a) Whether there are redundant movement can be reduced;

b) Is there a redundant walking can eliminate? If you can that you need to adjust the location of the tool and the material housekeeping position;

c) Whether operation can again an optimization way;

d) Whether tools and tooling can be improved;

e) Not value-added clip and correction can be reduced;

f) The wait before work because of the interference can be eliminated by adjusting job order those who interfere by standard;

g) Whether unstable preparation homework can be handed over to a professional to do it.

Table 2 Program analysis table of back panel skin weld

\begin{tabular}{|l|l|l|l|}
\hline According to the increment & time & Ratio & Notes \\
\hline VA & 180 & $19 \%$ & increment \\
\hline NVA & 182 & $19 \%$ & necessary non-increment \\
\hline W & 575 & $61 \%$ & waste \\
\hline According to the operation & time & Ratio & Notes \\
\hline 0 & 696 & $74 \%$ & operation \\
\hline$\rightarrow$ & 155 & $17 \%$ & carry \\
\hline$\square$ & 52 & $6 \%$ & inspection \\
\hline D & 34 & $4 \%$ & wait \\
\hline According to the cycle & time & ratio & Notes \\
\hline R & 832 & $89 \%$ & cycle \\
\hline UR & 105 & $11 \%$ & non-cycle \\
\hline
\end{tabular}

\section{Scheme Formulation and Analysis}

\subsection{Develop the Improvement Scheme}

Based on analysis to identify waste point in the process of program, specify the improvement measures. Problems in 6 class strokes: division of a layout, tool set-up mould, tool equipment, process optimization, material improvement. Clear out what specific improvement measures to do in 
the solution. Set improvement targets by the expected effect. During the acceptance period, projects that do not meet the target can't be solved and need to be corrected. Finally, form a improvement listing.

\subsection{Page Numbers}

\section{(1) Before the improvement}

Take $11^{\text {th }}$ and $12^{\text {th }}$ station of the first line in this factory, for example. To visually see staff work division of labor and time factors of each work and identify each employee's cycle time with the beat, we put the application in the analysis of the continuous action into the work elements that can allocate each other. It is mainly from analysis of three aspects: work time, work step and sequence.

The workers are allocated as shown below:

workers in $11^{\text {th }}$ station: Mr.A1 to Mr.A7

workers in $12^{\text {th }}$ station: Mr.A8 to Mr.A10

The person in charge for the problem is divided into three hierarchy: the group leader, the division boss and the supervisor. And problems are concretely divided into three type contents that can be improved:

a) The improvement within the station can be solved in a short time. The group leader as the person in charge ensures that when the first round of acceptance the improvement must be completed.

b) On the one hand, the improvement need to coordinate resources of section and unit. For example, adjusting works across a station need coordinating the internal unit. On the other hand, the improvement within the station can be solved but over a week.

c) Need to upgrade to the unit and pull workshop internal and external resources to solve by unit.

\section{(2) Implement improvement}

In the process of improving, the station improves itself as the dominant idea. One thing is to solve the level according to the problem and implement improvement scheme. The second is to upgrade the problem in time, which can't be improved at the deadline. The last thing is to Make the improvement effect curing after implementing improvement.

a) The improvement of the station can independently implement should be completed by the station. And hand in the improvement proposals to improve.

b) The division boss is responsible for the improvement that needs to be implemented across the station.

c) The supervisor is responsible for the external pulling to handle the improvement that needs to be implemented by pulling the external resource.

(3) Later improvement period

To the improvement has been implemented, check the improved efficiency of the state and adjust the operation time and work elements corresponding the improvement before:

a) The improvement within the station that can be solved in a short time should be all completed.

b) The improvement involved in the rest of the work elements needs keeping follow-up and observe the effects after eliminate waste.

(4) Equilibrium improvement

According to the project beat, balance the internal work station aiming at improving the unsaturated operation, operation which cannot reach the beat and operation with unbalanced between process assignments.

Firstly, ensure that $80 \%$ of workers operation saturation is close to the beat whereas $20 \%$ is close to nearly $80 \%$ of the beat.

Secondly, in order to meet the planning and saturation no less than $90 \%$, use the way of restructuring and balance operation again. The division boss must participate in the scene of the job allocation and allocate the effect after confirmation. 


\section{Effect Appraisal}

In this scheme, we derive statistical effects of each station after improvement and estimate the degree of support to improve the working unit target. Then check and accept the improvement results of all the operation units in each station.

The overall measure indexes of the project as following:

1) man-hour utilization rate

2) rate of production beat down

3) operation tend to the beat saturation

4) line balance rate of station and production line

According to index 1) to 3), here are the results in Table 3:

Table 3 Results

\begin{tabular}{|l|l|l|l|}
\hline item & Before the improvement & After the improvement & ratio \\
\hline Cycle time (CT) & 146.95 & 130.0 & $11.5 \%$ \\
\hline Project beat (TT) & 19.0 & 19 & 0 \\
\hline Target number of worker (CT/TT) & 7.7 & 6.8 & $11.5 \%$ \\
\hline Number of worker (NW) & 10.0 & 9 & $10.0 \%$ \\
\hline Working hours (TT*NW) & 190.00 & 171 & $10.0 \%$ \\
\hline
\end{tabular}

According to the index, line balance rate of production line, we analyze the line balance of the front and back wall professional group in the first line, of which the bar chart compares the improvement effect as following.

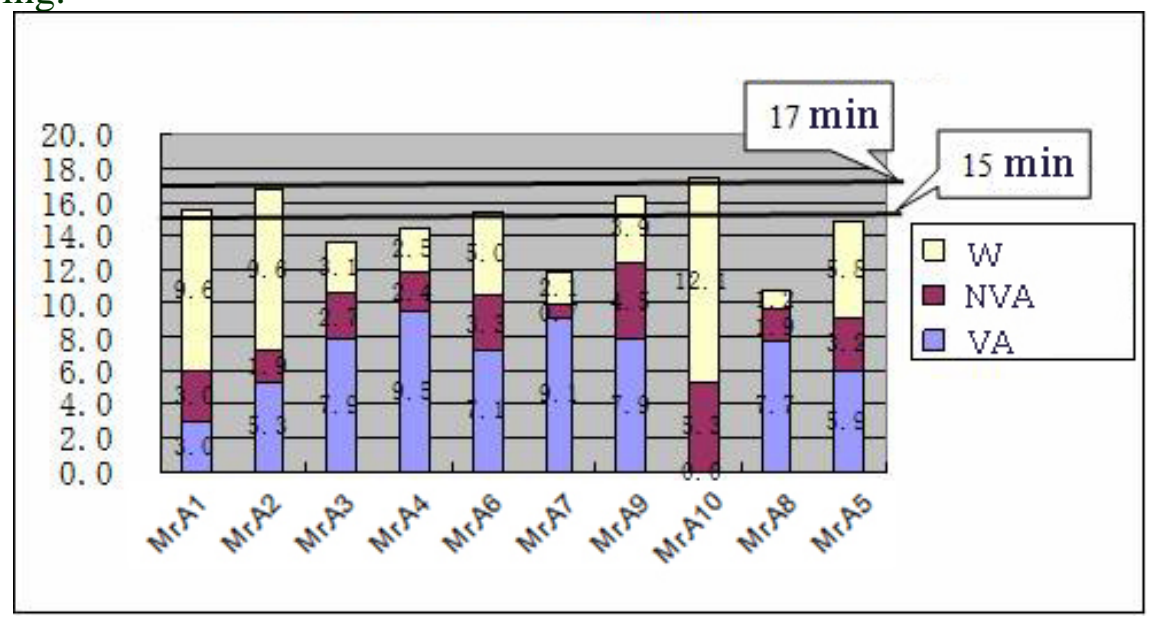

Fig. 1 the line balance analysis before improvement

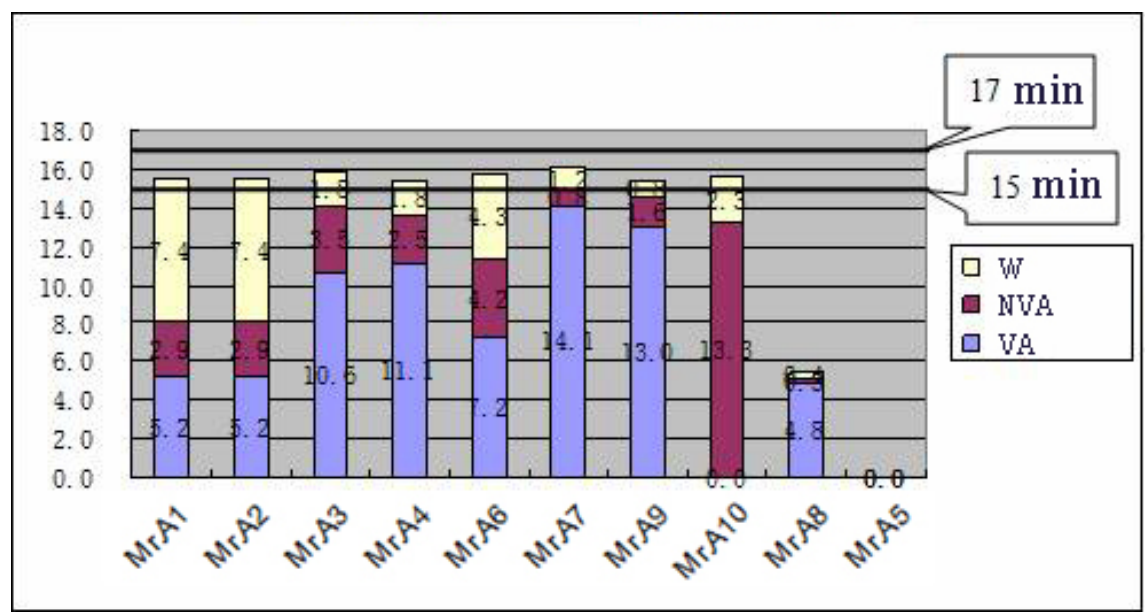

Fig. 2 the line balance analysis after improvement 


\section{Conclusion}

According to the data before improvement, each station exists some problems like unsaturated operation, operation that cannot approaching the target beats and unbalanced operation between processes. All of them are resolved in some extend after improvement. In addition, the workers' operation time is shortened obviously and personal value is higher than that of all after improving.

\section{References}

[1] Y. Liu. “Application in Enterprise Management with 80/20 Principle”. Enterprise Resource. Vol.09(2006), p. 40-41. 